\title{
Mycoplasma genitalium in Singapore is associated with Chlamydia trachomatis infection and displays high macrolide and Fluoroquinolone resistance rates
}

\author{
Tim Hart ${ }^{1 *}$, Wen Ying Tang ${ }^{1}$, Siti Aminah bte Mansoor ${ }^{2}$, Martin T. W. Chio ${ }^{2}$ and Timothy Barkham ${ }^{1}$
}

\begin{abstract}
Background: Mycoplasma genitalium is an emerging sexually transmitted infection, with increasing rates of resistance to fluroquinolones and macrolides, the recommended treatments. Despite this, M. genitalium is not part of routine screening for Sexually Transmitted Infections (STIS) in many countries and the prevalence of infection and patterns of disease remain to be determined in many populations. Such data is of particular importance in light of the reported rise in antibiotic resistance in $M$. genitalium isolates.

Methods: Urine and urethral swab samples were collected from the primary public sexual health clinic in Singapore and tested for C. trachomatis (CT) or N. gonorrhoeae (NG) infection and for the presence of M. genitalium. Antibiotic resistance in $\mathrm{M}$. genitalium strains detected was determined by screening for genomic mutations associated with macrolide and fluroquinolone resistance.

Results: We report the results of a study into $M$. genitalium prevalence at the national sexual health clinic in Singapore. M. genitalium was heavily associated with CT infection (8.1\% of cases), but present in only of $2.4 \%$ in CT negative cases and not independently linked to NG infection. Furthermore, we found high rates of resistance mutations to both macrolides (25\%) and fluoroquinolones (37.5\%) with a majority of resistant strains being dualresistant. Resistance mutations were only found in strains from patients with CT co-infection.

Conclusions: Our results support targeted screening of $\mathrm{CT}$ positive patients for $\mathrm{M}$. genitalium as a cost-effective strategy to reduce the incidence of $M$. genitalium in the absence of comprehensive routine screening. The high rate of dual resistance also highlights the need to ensure the availability of alternative antibiotics for the treatment of multi-drug resistant M. genitalium isolates.
\end{abstract}

Keywords: Mycoplasma genitalium, Chlamydia trachomatis, Neisseria gonorrhoea, Sexually transmitted diseases, Antibiotic resistance, Singapore

\footnotetext{
* Correspondence: drtimothyhart@gmail.com

'Tan Tock Seng Hospital, 11 Jalan Tan Tock Seng, Singapore 308433, Singapore

Full list of author information is available at the end of the article
}

C C The Author(s). 2020 Open Access This article is licensed under a Creative Commons Attribution 4.0 International License, which permits use, sharing, adaptation, distribution and reproduction in any medium or format, as long as you give appropriate credit to the original author(s) and the source, provide a link to the Creative Commons licence, and indicate if changes were made. The images or other third party material in this article are included in the article's Creative Commons licence, unless indicated otherwise in a credit line to the material. If material is not included in the article's Creative Commons licence and your intended use is not permitted by statutory regulation or exceeds the permitted use, you will need to obtain permission directly from the copyright holder. To view a copy of this licence, visit http://creativecommons.org/licenses/by/4.0/ The Creative Commons Public Domain Dedication waiver (http://creativecommons.org/publicdomain/zero/1.0/) applies to the data made available in this article, unless otherwise stated in a credit line to the data. 


\section{Background}

Mycoplasma genitalium is a sexually transmitted pathogen of rapidly increasing significance [1], which may cause cervicitis and urethritis in women and has been linked to pelvic inflammatory disease and infertility [2], as well as with non-gonococcal urethritis (NGU) in men [3]. Diagnosis of $M$. genitalium by bacterial culture is difficult due to requirements for specific media and prolonged incubation; in practice, diagnosis is constrained by a necessary reliance on molecular methods [4].

Treatment of $M$. genitalium has traditionally been with a single $1 \mathrm{~g}$ dose of azithromycin, using moxifloxacin as a second line agent. However, the recent increase in cases and the proportion of NGU caused by M. genitalium has been paralleled by a dramatic increase in resistance to both drug classes $[5,6]$, resulting in treatment failure [7]. M. genitalium is intrinsically resistant to beta-lactams and other antibiotics active at the cell wall, leaving realistic alternative treatment options limited. As quantitative antibiotic susceptibility tests are not widely performed due to the fastidious growth of the organism, monitoring of genetic markers of antibiotic resistance has become the mainstay of the clinical monitoring of M. genitalium susceptibility.

The significance of increased $M$. genitalium resistance is amplified in light of the commonality of co-infection with Chlamydia trachomatis (CT), a more established cause of urethritis. The standard first-line treatment of CT with single-dose oral azithromycin $1 \mathrm{~g}$, has been shown to impact macrolide resistance in M. genitalium in co-infected patients [8]. With this in mind, we aimed to establish, for the first time, the prevalence of M. genitalium infection in Singapore, the degree of co-infection with $\mathrm{CT}$, and levels of antibiotic resistance in these groups. Establishing these baselines is important to guide empirical therapy and will also allow us to gauge the rate of increase in, and significance of, resistance patterns in the future.

\section{Methods}

All samples were taken from patients attending the DSC Clinic (Department of Sexually Transmitted Infections Control) in Singapore, with institutional ethical approval. The DSC clinic is the principle public specialist clinic for Sexually Transmitted Infections in Singapore. The protocol in DSC is to test for CT and NG together using either Urethral Swabs, or from urine samples. Left over samples were collected after routine clinically directed testing for CT and Neisseria gonorrhoeae (NG), with the Cobas $4800 \mathrm{CT} / \mathrm{NG}$ system (Roche), at the clinic during a one-month period between May and June 2016. PCR was used to test these samples for $M$. genitalium. Sequencing was used to detect mutations associated with resistance to macrolides and fluoroquinolones.

\section{Genitalium PCR}

DNA was harvested from both positive and negative samples using automated extraction (Cobas 4800), followed by real-time PCR which simultaneously targeted both the $p d h D$ and $m g p B$ genes of $M$. genitalium. Primers and probes detecting the $p d h D$ gene were adapted from those previously published by Müller [9]: MG-041 (5' -CGGATCAAGACCAAGATACTTA ACTTT-3'), MG-042 (5'-AGCTTGGGTTGAGTCAAT GATAAAC) and MG-048 (HEX-5' -CCAGGGTTTGAA AAAGCACAACAAGCTG-3'-BHQ1). Primers and probes detecting the mgpB gene were adapted from those used by Jensen [10]: MgPa-355F (GAGAAATACC TTGATGGTCAGCAA), MgPa-432R (GTTAATATCA TATAAAGCTCTACCGTTGTTATC) and probe MgPa380 (FAM-ACTTTGCAATCAGAAGGT-BHQ1). Both primer/probe sets were included in the same PCR reaction $\left(12.5 \mu \mathrm{l}\right.$ SsoAdvanced $^{\mathrm{rm}}$ Universal SYBR Green Supermix (Biorad), $5 \mu \mathrm{M}$ each primer/probe set, $0.25 \mu \mathrm{l}$ MG-048 probe $(10 \mu \mathrm{M}), 0.6 \mu \mathrm{l} \mathrm{MgPa}-380$ probe $(10 \mu \mathrm{MM})$ and $5 \mu \mathrm{l}$ DNA in a $25 \mu \mathrm{l}$ reaction). PCR was carried out in a BioRad CFX96 machine with an initial denaturation of $95^{\circ} \mathrm{C}$ for $3 \mathrm{~min}$ and followed by 45 cycles of $94{ }^{\circ} \mathrm{C}$ for $15 \mathrm{~s}$ and $60^{\circ} \mathrm{C}$ for $30 \mathrm{~s}$ ). Samples were considered positive for M. genitalium only when both PCR results were positive. Where only one target was positive, the PCR was repeated to ensure two positive results (this was necessary for 3 samples all of which had low $\mathrm{Ct}$ values for amplification and in all 3 a positive result was obtained on repeat PCR).

\section{Sequencing}

$23 \mathrm{~S}$ rRNA gene sequencing of the $23 \mathrm{~S}$ ribosomal RNA gene from $16 \mathrm{M}$. genitalium positive samples was performed as described previously [11]. The gene was amplified using F1-Mg (5' GAAGGAGGTTAGCAATTTAT TGC) and R1-Mg (5' TTCTCTACATGGTGGTGTTT TG) and HotStar Taq (12.5 $\mu$ l HotStar Taq Buffer (Qiagen), $1 \mu \mathrm{M}$ each primer, $5 \mu \mathrm{l}$ extracted DNA, in a $30 \mu \mathrm{l}$ reaction). Sequencing was performed with PCR amplification primers and yielded around 150 nt sequence. Cycling conditions were $95^{\circ} \mathrm{C}$ for $15 \mathrm{~min}$ and then 45 cycles of $94{ }^{\circ} \mathrm{C}$ for $15 \mathrm{~s}, 58^{\circ} \mathrm{C}$ for $30 \mathrm{~s}, 72^{\circ} \mathrm{C}$ for $30 \mathrm{~s}$ and a final elongation of $3 \mathrm{~min}$ at $72{ }^{\circ} \mathrm{C}$. Sequences (GenBank accession MK411350-MK411365) were manually checked for the presence of alterations at nucleotide 2058 or 2058 (E. coli numbering).

GyrA or parC sequencing was carried out as previously described [12] using either MG-GYRA-A (CGTCGTGTTCTTTATGGTGC) and MG-GYRA-B (ATAACGYYGTGCAGCAGGTC) primers or MGPARC-A (TGGGCTTAAAACCCACCACT) and MGPARC-B (CGGGTTTCTGTGTAACGCAT). HotStar Taq was again used, with $10 \mu \mathrm{M}$ each primer and $5 \mu \mathrm{l}$ 
extracted DNA (total $30 \mu \mathrm{l}$ volume) and cycling was as for $23 \mathrm{~S}$ rRNA sequencing. Comparison of the resulting 150 nucleotide sequences (GenBank accession MK411366- MK411397) with previously published mutations was through manual alignment.

\section{Results}

Of 472 samples screened for CT and NG, 358 were urine samples and 114 urethral swabs. A total of 185 samples were found to be PCR positive for either CT, NG, or positive for both, with a total of 287 negative samples (Table 1). CT was found in $22.3 \%$ urine samples and $23.7 \%$ urethral swabs. NG was more frequently isolated from urethral swabs than urine samples, whether as the sole isolate $(17.6 \%$ vs $11.7 \%$ respectively) or in combination with CT (6.1\% vs $2.5 \%)$. However, overall there was no statistically significant difference between NG, CT or M. genitalium isolation from urethral swabs or urine.

To estimate the relative rates of $M$. genitalium in CT and NG positive and negative samples, we randomly selected 184 samples from the 287 CT/NG negative samples and performed an $M$. genitalium PCR in comparison to the $185 \mathrm{CT} / \mathrm{NG}$ positive samples. Our results show an association of M. genitalium infection with CT co- infection (Table 2). The rate of M. genitalium infection in patients positive for CT was $8.1 \%$ (10/123, including a patient with both $\mathrm{CT}$ and NG) but $M$. genitalium was not detected in any of 62 patients with NG alone. The rate of $M$. genitalium in CT negative samples (including CT negative/NG positive samples) was $2.4 \%(6 / 246)$. This corresponds to an odds ratio of

Table 1 Detection of M. genitalium, and C. trachomatis or N. gonorrhoeae in Urine Samples (A) and Urethral Swabs (B) with respect to the presence (+ve) or absence $(-v e)$ of $M$. genitalium. Percentages in parentheses refer to the proportion of total samples)

\begin{tabular}{|c|c|c|c|c|}
\hline & & \multicolumn{2}{|c|}{ M. genitalium } & \multirow[t]{2}{*}{ Total } \\
\hline & & +ve & -ve & \\
\hline \multirow[t]{6}{*}{ A } & Urine & & & \\
\hline & $\mathrm{CT}$ & $7(2 \%)$ & 73 (20.4\%) & $80(22.3 \%)$ \\
\hline & NG & 0 & 42 (11.7\%) & 42 (11.7\%) \\
\hline & both & $1(0.3 \%)$ & $8(2.2 \%)$ & $9(2.5 \%)$ \\
\hline & negative & $5(1.4 \%)$ & $222(62.0 \%)$ & $227(63.4 \%)$ \\
\hline & total & $13(3.6)$ & 345 (96.4) & 358 \\
\hline \multirow[t]{6}{*}{ B } & Swab & & & \\
\hline & CT & $2(1.8 \%)$ & 25 (21.9\%) & 27 (23.7\%) \\
\hline & NG & 0 & $20(17.5 \%)$ & $20(17.5 \%)$ \\
\hline & both & 0 & 7 (6.1\%) & $7(6.1 \%)$ \\
\hline & negative & $1(0.9 \%)$ & 59 (51.8\%) & $60(52.6 \%)$ \\
\hline & total & $3(2.6 \%)$ & 111 (97.4\%) & 114 \\
\hline
\end{tabular}

3.54 for MG infection in patients with C. trachomatis infection as compared to $C$. trachomatis negative patients $(P=0.017,95 \%$ Confidence Interval of 1.26 to 9.98$)$.

To determine macrolide and fluoroquinolone resistance rates in M. genitalium, we sequenced the genomic areas noted to be responsible for macrolide resistance (23S ribosomal RNA) [11, 13] and fluoroquinolone resistance (parC or gyrA genes) [14]. 6 of our 16 M. genitalium isolates contained sequences previously associated with antibiotic resistance [14]. Interestingly, resistance mutations were exclusively found in those isolates which were also positive for C. trachomatis (Table 3A).

We found mutations in the 23S rRNA sequence (previously shown to confer macrolide resistance) in four of our M. genitalium positive samples (25\%), and parC mutations (previously associated with fluoroquinolone resistance) in 6 samples (37.5\%). The antibiotic resistance noted in our isolates is relatively diverse (Table 3B), demonstrating both of the mutations linked to macrolide resistance (nucleotides 2508 and 2509 of $23 \mathrm{~S}$ rRNA [11]) and four different mutations in the parC gene associated with fluoroquinolone resistance [14] (Ser 83 $\rightarrow$ Asn, Ser84 $\rightarrow$ Pro, Asp87 $\rightarrow$ Tyr and Ser83 $\rightarrow$ Ile). Two thirds of the resistant isolates contained both fluoroquinolone and macrolide resistance mutations (Table 3B). No mutations were found in the gyrA gene and, other than a $\mathrm{T} \rightarrow \mathrm{A}$ transition at position 1975 of the $23 \mathrm{~S}$ gene of one isolate, there were no other mutations found.

\section{Discussion}

Our study, the first of M. genitalium in Singapore, revealed strikingly different prevalences of $M$. genitalium depending on the presence of Chlamydia trachomatis co-infection: 2.4\% M. genitalium positive samples in CT negative individuals and $8.1 \%$ in CT positive patients. The DSC clinic is both the major government sexual health clinic and the site of the mandatory screening of licenced commercial sex workers (CSWs) in Singapore. It is a relative weakness of this study that we do not have precise demographic details for our cohort, but they will have comprised both CSWs and non-CSW patients undergoing CT/NG testing for clinical urethritis. As such, our data would be expected to overestimate the prevalence of $M$. genitalium in the general population in Singapore. Previously reported prevalences of M. genitalium have varied considerably depending on the population studied and our findings compare with rates as low $1.2 \%$ in the general UK population [15] and as high as $22.4 \%$ in adolescent women in the US [16]. Within studies based on CSWs, or in sexual health clinics, reported rates of $M$. genitalium prevalence tend to be higher than those found in our study, leading to a conclusion of a relatively low prevalence of M. genitalium in Singapore, even in those 
Table 2 Prevalence of M. genitalium in C. trachomatis and N. gonorrhoeae positive and negative samples

\begin{tabular}{llllll}
\hline M. genitalium & CT alone & NG alone & CT/NG Dual Infection ${ }^{\text {a }}$ & CT/NG Negative & Total \\
\hline positive & $9(7.3 \%)$ & 0 & $1(6.3 \%)$ & $6(3.3 \%)$ & $16(4.3 \%)$ \\
negative & 98 & 62 & 15 & 178 & 353 \\
Total & 107 & 62 & 16 & 184 & 369 \\
\hline
\end{tabular}

Percentage of positive samples are shown in parentheses

${ }^{\text {a }}$ Dual infection refers to samples in which both $C$. trachomatis and $N$. gonorrhoeae were detected

at risk of infection [17]. This fits a general pattern of lower rates of Sexually Transmitted Infections (STI) in Singapore than the global average, however, it should be noted that this is in the context of an overall increase of STIs in the country [18].

Our study was designed to determine the relative prevalence of $M$. genitalium in CT/NG infected and uninfected patients. Such a correlation has been noted in some studies $[15,16]$ but has been absent in others [19]. Our results show that, not only is there a heavy association of M. genitalium infection with CT infection in Singapore (odds ratio 3.5 as compared with CT PCR negative samples), but the odds ratio for this association (3.5) is much larger than previously published odds/hazard ratios of 1.9-2.5 [16, 20, 21]. While the association of CT and M. genitalium could result from shared risk factors for the transmission of these STIs, in our study, there was no association of M. genitalium with NG, which would also share similar risks for transmission, implying either a more a causal association between $\mathrm{CT}$ and $M$.

Table 3 Antibiotic resistance in M. genitalium exclusively found in C. trachomatis co-infected samples (A), with a high rate of coresistance to macrolides (23S) and fluoroquinolones (parC) in the resistant isolates $(B)$

A

$\begin{array}{llll} & \text { Wild-type } & \begin{array}{l}\text { Resistance } \\ \text { mutation }\end{array} & \text { Total } \\ \text { C. trachomatis } & 4 & 5 & 9 \\ \text { N. gonorrhoeae } & 0 & 0 & 0 \\ \begin{array}{l}\text { CT/NG dual } \\ \text { infection }\end{array} & 0 & 1 & 1 \\ \text { CT/NG negative } & 6 & 0 & 6 \\ \text { Total } & 10 & 6 & 16\end{array}$

B

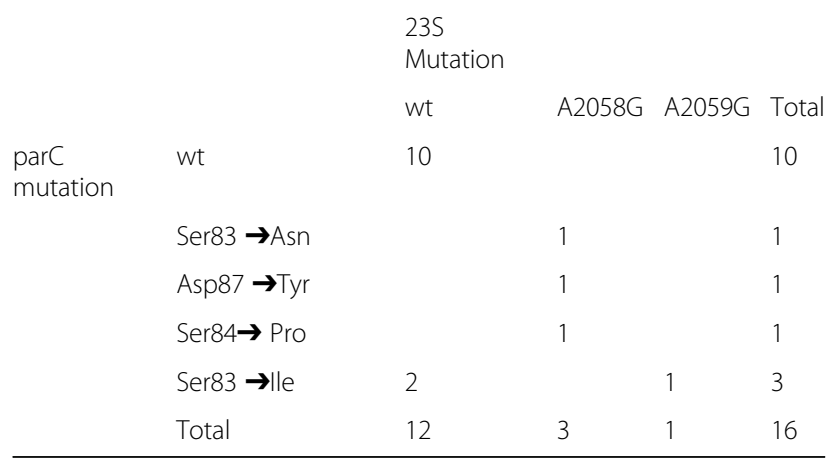

gentialium infection, or at least a more nuanced epidemiological association.

The importance of considering CT co-infection while evaluating the burden of disease due to $M$. genitalium is highlighted by the concerning patterns of resistance in our samples. M. genitalium is very infrequently diagnosed in Singapore and thus very rarely specifically treated, whereas treatment of CT (or symptomatic urethritis) is common, with single-dose azithromycin. While single dose macrolide treatment was previously advocated for $M$. genitalium, evidence is growing to suggest that, in practise a five-day course of macrolides should be used to ensure $M$. genitalium eradication [7, 22]. Resistance mutations in our study were exclusively found in $M$. genitalium isolates taken from patients with $\mathrm{CT}$ co-infection. Although involving relatively small datasets due to the low prevalence of $M$. genitalium in Singapore, our data strongly supports a conclusion that a single dose macrolide is indeed non-curative with respect to $M$. genitalium and that the treatment of $\mathrm{CT}$ is, at least to some extent, driving $M$. genitalium resistance. In this respect, our study could be improved with clinical data on our patients' past exposure to macrolides to definitively show that repeated treatment of serially acquired or recurrent CT infections, or use of macrolides or fluroquinolones to treat other infections, is associated with $M$. genitalium antibiotic resistance in Singapore. Our data is unusual in that resistance to macrolides is usually much higher than that of fluoroquinolones [19, 23-25], although predominance of fluoroquinolone resistance has previously also been noted [26, 27]. With respect to the latter issue, we noted that although fluoroquinolones are rarely used as first-line treatment of NGU in the DSC clinic in Singapore, we still note a high resistance to these infections in our sample. Such resistance may be due to a high frequency of antibiotic use for other conditions, such as respiratory or urinary tract infection. A high general antibiotic pressure from fluoroquinolones in Singapore is implied by recent findings of identical resistance mutations in the $23 \mathrm{~S}$ rRNA of $M$. pneumoniae [28] in Singaporean patients.

The high rate of overall resistance $(37.75 \%$ of our samples resistant to either fluoroquinolones or macrolides) and multi-drug resistance $(62.25 \%$ of our resistant 
samples had resistance to both macrolides and fluoroquinolones) follows the global trend of increasing levels of macrolide and fluoroquinolone resistance in M. genitalium $[6,24,26,27]$. The global situation of a slow, unnoticed accumulation of mutations to the only available therapies in patients with undiagnosed M. genitalium infection is concerning in light of the serious sequelae of untreated $M$. genitalium. The situation is compounded in Singapore, in which many of the newer antibiotics which have shown efficacy against $M$. genitalium are currently unavailable, in particular pristinamycin, a commonly recommended third line antibiotic [29]. Our results support the argument for close monitoring of antibiotic resistance in M. genitalium in Singapore, as in the rest of the world. Management of such resistance relies on timely diagnosis and appropriate treatment, ideally with subsequent confirmation of clearance of $M$. genitalium infections, but although diagnosis of $M$. genitalium has never been easier in light of novel and more convenient molecular tests [4], M. genitalium is often not part of routine screening or tested for in cases of NGU $[8,30]$. Evidently the ideal approach would be to consider M. genitalium in all cases of NGU, routine screening and monitoring of populations at risk of high M. genitalium transmission, and susceptibility-guided therapy of treatment failures [31]. However, where this is not feasible, we believe that the close association of $M$. genitalium and $\mathrm{CT}$ in terms of infection and antibiotic resistance suggests that ensuring adequate diagnosis and treatment of M. genitalium in CT infected patients may constitute a more cost-effective approach in a situation of finite resources. Furthermore, in light of the high rates of (multi-drug) resistance in the $M$. genitalium noted in this study we agree with recently published guidelines [32] that such treatment should extend beyond a single dose. The high frequency of dual -resistant strains of M. genitalium in our study highlights the urgent need to make some of novel antibiotics, such as pristinamycin, which are considered third-line options in other countries, available in Singapore. Overall, our data, revealing a low but significant prevalence of $M$. genitalium in Singapore, associated with a high level of resistance to the available treatment choices, highlight the importance of developing a robust approach to diagnosis and treatment of M. genitalium, whether general or targeted, to avoid the emergence of untreatable M. genitalium in the region.

\section{Conclusions}

This study has established some basic epidemiological benchmarks with respect to $M$. genitalium infection in Singapore. Our results point to a low prevalence in our study population, despite being based in a sexual health clinic, where prevalences are typically high; suggesting the potential to limit the emergence of $M$. genitalium in the country. Despite this, we found an alarmingly high level of resistance to the recommended first line antibiotics on a background of a low rate of screening for $M$. genitalium in the country. The strong association of $M$. genitalium with CT, for which there is more frequent testing, suggests that, at a minimum, patients with $\mathrm{CT}$ in Singapore should be screened for M. genitalium. Furthermore, treatment of CT (as well as other infections) should be undertaken with due consideration to the high resistance rates of $M$. genitalium. Our study highlights the need for a broader investigation of $M$. genitalium in Singapore and re-iterates the importance of ensuring that novel alternatives to macrolide and fluoroquinolone therapy are available.

\section{Abbreviations \\ CSW: Commercial Sex Worker; Ct: threshold cycle value; CT: Chlamydia trachomatis; DNA: deoxyribonucleic acid; DSC clinic: Department of Sexually Transmitted Infections Control clinic; NG: Neisseria gonorrhoea; NGU: non- gonorrhoeal urethritis; PCR: Polymerase Chain Reaction; rRNA: ribosomal Ribonucleic Acid; STI: Sexually Transmitted Infection}

\section{Acknowledgements}

Not applicable.

\section{Authors' contributions}

TB: Project design and critical review of manuscript. TH: Data analysis and manuscript preparation. WYT: Sample collection, PCR and sequencing. SAbM: Sample collection. MTWC: Project design and critical review of manuscript. All authors have read and approved the manuscript.

\section{Author information}

TH has an MSc in the Control of Infectious Diseases from the London School of Hygiene and Tropical Medicine, a PhD in Molecular Virology from the University of Glasgow, an MD from Duke-NUS Graduate Medical School in Singapore.

\section{Funding}

Sample collection, sample preparation, PCR and sequencing work was funded by the Molecular Biology Research Laboratory, Tan Tock Seng Hospital, Singapore.

\section{Availability of data and materials}

Sequences obtained in this study have been deposited in GenBank (Accession MK411350- MK411397). Any other data referenced in this report is available from the corresponding author on reasonable request.

Ethics approval and consent to participate

Ethical approval was granted with a waiver of the need to acquire informed consent (NHG DSRB Ref: 2013/00355).

\section{Consent for publication}

Not applicable. No individual person's data was analysed for the purposes of this study.

Competing interests

There are no conflicts of interest to declare.

\section{Author details}

${ }^{1}$ Tan Tock Seng Hospital, 11 Jalan Tan Tock Seng, Singapore 308433, Singapore. ${ }^{2}$ Department of Sexually Transmitted Infections Control Clinic, 31 Kelantan Ln, Singapore 200031, Singapore. 
Received: 2 December 2019 Accepted: 7 April 2020

\section{Published online: 28 April 2020}

\section{References}

1. Unemo M, Jensen JS. Antimicrobial-resistant sexually transmitted infections: gonorrhoea and Mycoplasma genitalium. Nat Rev Urol. 2017;14:139-52. https://doi.org/10.1038/nrurol.2016.268.

2. McGowin CL, Anderson-Smits C. Mycoplasma genitalium: An Emerging Cause of Sexually Transmitted Disease in Women. PLOS Pathog. 2011;7: e1001324. https://doi.org/10.1371/journal.ppat.1001324.

3. Horner PJ, Martin DH. Mycoplasma genitalium Infection in Men. J Infect Dis. 2017;216:S396-405. https://doi.org/10.1093/infdis/jix145.

4. Munson E. Molecular Diagnostics Update for the Emerging (If Not Already Widespread) Sexually Transmitted Infection Agent Mycoplasma genitalium: Just About Ready for Prime Time. J Clin Microbiol. 2017;55:2894-902. https://doi.org/10.1128/JCM.00818-17.

5. Manhart LE, Jensen JS, Bradshaw CS, Golden MR, Martin DH. Efficacy of Antimicrobial Therapy for Mycoplasma genitalium Infections. Clin Infect Dis Off Publ Infect Dis Soc Am. 2015;61(Suppl 8):S802-17. https://doi.org/10. 1093/cid/civ785.

6. Murray GL, Bradshaw CS, Bissessor M, Danielewski J, Garland SM, Jensen JS, et al. Increasing macrolide and Fluoroquinolone resistance in mycoplasma genitalium. Emerg Infect Dis. 2017;23:809-12. https://doi.org/10.3201/ eid2305.161745.

7. Lau A, Bradshaw CS, Lewis D, Fairley CK, Chen MY, Kong FYS, et al. The Efficacy of Azithromycin for the Treatment of Genital Mycoplasma genitalium: A Systematic Review and Meta-analysis. Clin Infect Dis Off Publ Infect Dis Soc Am. 2015;61:1389-99. https://doi.org/10.1093/cid/civ644.

8. Pond MJ, Nori AV, Witney AA, Lopeman RC, Butcher PD, Sadiq ST. High prevalence of antibiotic-resistant mycoplasma genitalium in nongonococcal urethritis: the need for routine testing and the inadequacy of current treatment options. Clin Infect Dis Off Publ Infect Dis Soc Am. 2014;58:631-7. https://doi.org/10.1093/cid/cit752.

9. Müller EE, Venter JME, Magooa MP, Morrison C, Lewis DA, Mavedzenge SN. Development of a rotor-gene real-time PCR assay for the detection and quantification of Mycoplasma genitalium. J Microbiol Methods. 2012;88:3115. https://doi.org/10.1016/j.mimet.2011.12.017.

10. Jensen JS, Björnelius E, Dohn B, Lidbrink P. Use of TaqMan 5' Nuclease RealTime PCR for Quantitative Detection of Mycoplasma genitalium DNA in Males with and without Urethritis Who Were Attendees at a Sexually Transmitted Disease Clinic. J Clin Microbiol. 2004;42:683-92. https://doi.org/ 10.1128/JCM.42.2.683-692.2004

11. Touati A, Peuchant O, Jensen JS, Bébéar C, Pereyre S. Direct detection of macrolide resistance in mycoplasma genitalium isolates from clinical specimens from France by use of real-time PCR and melting curve analysis. J Clin Microbiol. 2014;52:1549-55. https://doi.org/10.1128/JCM.03318-13.

12. Shimada Y, Deguchi T, Nakane K, Masue T, Yasuda M, Yokoi S, et al. Emergence of clinical strains of mycoplasma genitalium harbouring alterations in ParC associated with fluoroquinolone resistance. Int J Antimicrob Agents. 2010;36:255-8. https://doi.org/10.1016/j.jjantimicag.2010. 05.011.

13. Jensen JS, Bradshaw CS, Tabrizi SN, Fairley CK, Hamasuna R. Azithromycin Treatment Failure in Mycoplasma genitalium-Positive Patients with Nongonococcal Urethritis Is Associated with Induced Macrolide Resistance. Clin Infect Dis. 2008;47:1546-53. https://doi.org/10.1086/593188.

14. Hamasuna R, Le PT, Kutsuna S, Furubayashi K, Matsumoto M, Ohmagari N, et al. Mutations in ParC and GyrA of moxifloxacin-resistant and susceptible Mycoplasma genitalium strains. PLOS ONE. 2018;13:e0198355. https://doi. org/10.1371/journal.pone.0198355.

15. Sonnenberg P, Ison CA, Clifton S, Field N, Tanton C, Soldan K, et al. Epidemiology of mycoplasma genitalium in British men and women aged 16-44 years: evidence from the third National Survey of sexual attitudes and lifestyles (Natsal-3). Int J Epidemiol. 2015;44:1982-94. https://doi.org/10. 1093/ije/dyv194.

16. Huppert JS, Mortensen JE, Reed JL, Kahn JA, Rich KD, Hobbs MM. Mycoplasma genitalium Detected by Transcription-Mediated Amplification Is Associated With Chlamydia trachomatis in Adolescent Women. Sex. Transm. Dis. [Internet] 2008 [cited 2018 10];35. doi: https://www.ncbi.nlm. nih.gov/pmc/articles/PMC3807598/doi:10.1097/OLQ.0b013e31815abac6.

17. Baumann L, Cina M, Egli-Gany D, Goutaki M, Halbeisen FS, Lohrer G-R, et al. Prevalence of $<$ em $>$ Mycoplasma genitalium $</$ em $>$ in different population groups: systematic review and meta-analysis. Sex. Transm. Infect. [Internet] 2018 9;doi: http://sti.bmj.com/content/early/2018/02/08/sextrans-2017-0533 84.abstractdoi: https://doi.org/10.1136/sextrans-2017-053384.

18. Sen $\mathrm{P}$, Chio MT, Tan H-H, Chan RK. Rising trends of STIs and HIV infection in Singapore-- a review of epidemiology over the last 10 years (1994 to 2003). Ann Acad Med Singap. 2006;35:229-35.

19. Getman D, Jiang A, O'Donnell M, Cohen S. Mycoplasma genitalium prevalence, Coinfection, and macrolide antibiotic resistance frequency in a multicenter clinical study cohort in the United States. J Clin Microbiol. 2016; 54:2278-83. https://doi.org/10.1128/JCM.01053-16.

20. Cohen CR, Nosek M, Meier A, Astete SG, Iverson-Cabral S, Mugo NR, et al. Mycoplasma genitalium infection and persistence in a cohort of female sex workers in Nairobi. Kenya Sex Transm Dis. 2007;34:274-9. https://doi.org/10. 1097/01.olq.0000237860.61298.54.

21. Tosh AK, Van Der Pol B, Fortenberry JD, Williams JA, Katz BP, Batteiger BE, et al. Mycoplasma genitalium among adolescent women and their partners. J Adolesc Health Off Publ Soc Adolesc Med. 2007;40:412-7. https://doi.org/ 10.1016/j.jadohealth.2006.12.005.

22. Horner $P$, Ingle SM, Garrett F, Blee K, Kong F, Muir $P$, et al. Which azithromycin regimen should be used for treating Mycoplasma genitalium? A meta-analysis. Sex Transm Infect. 2018;94:14-20. https://doi.org/10.1136/ sextrans-2016-053060.

23. Dionne-Odom J, Geisler WM, Aaron KJ, Waites KB, Westfall AO, Van Der Pol $B$, et al. High Prevalence of Multidrug-Resistant Mycoplasma genitalium in Human Immunodeficiency Virus-Infected Men Who Have Sex With Men in Alabama. Clin Infect Dis. 2018;66:796-8. https://doi.org/10.1093/cid/cix853.

24. Gratrix J, Plitt S, Turnbull L, Smyczek P, Brandley J, Scarrott R, et al. Prevalence and antibiotic resistance of Mycoplasma genitalium among STI clinic attendees in Western Canada: a cross-sectional analysis. BMJ Open. 2017;7:e016300. https://doi.org/10.1136/bmjopen-2017-016300.

25. Hadad R, Golparian D, Lagos AC, Ljungberg J, Nilsson P, Jensen JS, et al. Macrolide and fluoroquinolone resistance in mycoplasma genitalium in two Swedish counties, 2011-2015. APMIS Acta Pathol Microbiol Immunol Scand. 2018;126:123-7. https://doi.org/10.1111/apm.12792.

26. Kikuchi M, Ito S, Yasuda M, Tsuchiya T, Hatazaki K, Takanashi M, et al. Remarkable increase in fluoroquinolone-resistant Mycoplasma genitalium in Japan. J Antimicrob Chemother. 2014;69:2376-82. https://doi.org/10.1093/ jac/dku164.

27. Shipitsyna E, Rumyantseva T, Golparian D, Khayrullina G, Lagos AC, Edelstein I, et al. Prevalence of macrolide and fluoroquinolone resistance-mediating mutations in mycoplasma genitalium in five cities in Russia and Estonia. PLoS One. 2017;12:e0175763. https://doi.org/10.1371/journal.pone.0175763.

28. Loo LH, Soong HY, Maiwald M, Tee NW. Assessment of genotypic macrolide resistance among mycoplasma pneumoniae infections in children in Singapore. Ann Acad Med Singap. 2017;46:290-2.

29. Soni S, Horner P, Rayment M, Pinto-Sander N, Naous N, Parkhouse A, et al. 2018 BASHH UK national guideline for the management of infection with Mycoplasma genitalium. Soni;27.

30. Birger R, Saunders J, Estcourt C, Sutton AJ, Mercer CH, Roberts T, et al. Should we screen for the sexually-transmitted infection Mycoplasma genitalium ? Evidence synthesis using a transmission-dynamic model. Sci Rep. 2017;7:16162. https://doi.org/10.1038/s41598-017-16302-8.

31. Nijhuis RHT, Severs TT, Van der Vegt DSJM, Van Zwet AA, Kusters JG. High levels of macrolide resistance-associated mutations in mycoplasma genitalium warrant antibiotic susceptibility-guided treatment. J Antimicrob Chemother. 2015;70:2515-8. https://doi.org/10.1093/jac/dkv136.

32. Jensen JS, Cusini M, Gomberg M, Moi H. 2016 European guideline on mycoplasma genitalium infections. J Eur Acad Dermatol Venereol JEADV. 2016;30:1650-6. https://doi.org/10.1111/jdv.13849.

\section{Publisher's Note}

Springer Nature remains neutral with regard to jurisdictional claims in published maps and institutional affiliations. 